\title{
25 Research Soure \\ The Acute Toxicity of Thulium to Hyalella Azteca and the Influence of Toxicity Modifying Factors.
}

\author{
Alexandria Loveridge \\ Wilfrid Laurier University \\ D. Scott Smith \\ Wilfrid Laurier University \\ Jim C. McGeer ( $\sim$ jmcgeer@wlu.ca ) \\ Wilfrid Laurier University https://orcid.org/0000-0002-9267-8999
}

\section{Research Article}

Keywords: toxicity, thulium, influence of toxicity, modifying factors, demand, earth elements, organic matter

Posted Date: August 10th, 2021

DOI: https://doi.org/10.21203/rs.3.rs-779765/v1

License: (c) (i) This work is licensed under a Creative Commons Attribution 4.0 International License. Read Full License 


\section{Abstract}

The demand for rare earth elements (REEs) is growing and as a result, environmental exposure is a concern. The objective of this research was to evaluate the acute toxicity of Tm to Hyalella azteca and to understand the potential for toxicity modification by dissolved organic matter (DOM) and the cations $\mathrm{Ca}^{2+}, \mathrm{Mg}^{2+}$ and $\mathrm{Na}^{+}$. Standard methods were followed for $96 \mathrm{~h}$ static exposures in a medium with a hardness of $60 \mathrm{mg} \mathrm{CaCO} / 3 / \mathrm{LH}$ of 7.3 at $23^{\circ} \mathrm{C}$. H azteca neonates (2-9 d of age) were used and in unmodified media the LC50 concentration was 3.4 $\mu \mathrm{M}(95 \% \mathrm{Cl}$ 2.9-3.9 $\mu \mathrm{M} ; 573 \mu \mathrm{g} / \mathrm{L}$ (482-663)) based on measured dissolved concentrations at the end of the test. Tests done with different concentrations of $\mathrm{Ca}$ $(0.25,0.5$ and $1.5 \mathrm{mM})$ did not show consistent trends and there was no clear evidence of a protective effect from $\mathrm{Ca}$. Variations in $\mathrm{Na}(0.26,0.5$ and $1.6 \mathrm{mM})$ resulted in no significant changes in toxicity. Similarly, $\mathrm{Mg}(0.07,0.14$ and $0.4 \mathrm{mM})$ did not result in significant changes in LC50 values, except for a reduction in toxicity for measured total $\mathrm{Tm}$ at the lowest $\mathrm{Mg}$ concentration. Our results indicate that $\mathrm{Tm}$ toxicity is not influence by cationic competition ( $\mathrm{Ca}, \mathrm{Na}$ and $\mathrm{Mg}$ ). Dissolved organic matter (sourced from Luther Marsh ON) offered significant protection against Tm toxicity. Additions over $3 \mathrm{mg} \mathrm{DOC/L}$ resulted in significantly increased LC50 values. This study contributes toward understanding the toxicity of Tm and the importance of considering dissolved organic matter in estimating the potential for environmental risk of REEs.

\section{Introduction}

Global demand for REEs has increased dramatically in recent years and Canada is home to significant deposits potentially making it a leading global producer (Humphries 2013; Yin et al. 2021). There is limited information about the potential environmental impacts of REEs in aquatic systems (Gwenzi et al. 2018) and this is particularly the case for thulium (Tm). In a comparison of acute toxicities, Borgmann et al. (2005) found Tm to have the lowest LC50 value to Hyalella azteca with a measured dissolved concentration of $0.01 \mu \mathrm{g} / \mathrm{L}(0.00059 \mu \mathrm{M})$ in very soft water $\left(12 \mathrm{mg} \mathrm{CaCO}_{3} / \mathrm{L}\right)$. This dissolved concentration was associated with a nominal exposure concentration of $721 \mu \mathrm{g} / \mathrm{L}(4.3 \mu \mathrm{M})$ indicating that the majority of the Tm in test solutions had precipitated (Borgmann et al. 2005). In spite of the fact that Tm appears to have a higher toxicity compared to the other REEs tested by Borgmann et al. (2005) there have been few studies (if any) on the aquatic toxicity of this heavy REE.

It is well known that the aquatic toxicity of inorganic forms of metals can be influenced by its geochemical speciation. For many of the well studied metals, acute toxicity results from the uptake of free metal ions into the organism and the resulting disruption of essential ion balance (Niyogi and Wood, 2004; Mebane et al. 2020). Toxicity modifying factors (TMFs) for metals are grouped as either cations that compete for uptake, or negatively charged ligands that complex free ions and thereby reduce bioavailability (Di Toro et al. 2001; Santore et al. 2001). Toxicity reduction through cationic competition occurs because uptake of the toxic free metal cation occurs via mechanisms for uptake of essential ions, particularly $\mathrm{Ca}^{2+}, \mathrm{Mg}^{2+}$ or $\mathrm{Na}^{+}$, and therefore is dependent on concentrations of the latter. This is 
particularly the case for monovalent and divalent metals such as $\mathrm{Cu}^{2+}, \mathrm{Zn}^{2+}, \mathrm{Pb}^{2+}, \mathrm{Ag}^{+}$and $\mathrm{Co}^{2+}\left(\mathrm{Niyogi}^{2}\right.$ and Wood, 2004). Anions such as $\mathrm{HCO}_{3}{ }^{-}$and $\mathrm{Cl}^{-}$along with negatively charged moieties within dissolved organic matter (DOM) form complexes with free metal ions and thereby reduced the concentration of the most toxic form of the metal without changing the overall total concentration in solution (Mebane et al. 2020). DOM is recognized as having an important role in the mitigation of metal toxicity (Wood et al. 2011). It is ubiquitous in natural aquatic systems where it arises from both autochthonous and terrigenous inputs with the latter representing a key input to food webs (Tanentzap et al. 2014). As a large, heterogeneous, complex molecule, metal ions bind to functional groups such as carboxylates and phenols (Al-Reasi et al., 2013).

Complexation and competition have been shown to be relevant for the uptake and toxicity of some REEs but there is very little information for Tm. For example, the study of Vukov et al. (2016) showed that the addition of $\mathrm{Ca}^{2+}$ and also $\mathrm{Na}^{+}$to Dy exposures with $\mathrm{H}$ azteca resulted in significant decreases in acute toxicity. In that same study, increased concentrations of DOM also resulted in decreased toxicity. La toxicity to Daphnia carinata was shown to decrease with increased hardness (Barry and Mehan 2000), indicating that cations such as $\mathrm{Ca}^{2+}$ and $\mathrm{Mg}^{2+}$ may compete with $\mathrm{La}^{3+}$ cations for uptake and/or binding to the site of toxic action. Borgmann et al. (2005) also saw decreases in the toxicity to H. azteca for some of the REEs with an increase in water hardness although in that study water chemistry was altered by dilution and therefore changes in hardness co-occurred with changes in other TMFs. However, in the case of Tm there were no differences in the $7 \mathrm{~d}$ LC50 values between hard and soft water but only nominal concentrations were reported (Borgman et al. 2005). $\mathrm{Ca}^{2+}$ as well as dissolved organic matter were shown to reduce the uptake and toxicity of Ce to the algal species Chlamydomonas reinhardtii (El-Akl et al. 2015). Zhao and Wilkinson (2015) used the same species and tested the uptake of Tm in the presences of known complexing ligands, citric acid, malic acid, nitrilotriacetic acid. Internalization of Tm into algae was found to be correlated with $\mathrm{Tm}^{3+}$ concentrations but there was also uptake of ligand bound Tm (Zhao and Wilkinson 2015). The authors were able to rule out direct uptake of Tm complexes and also uptake via anion channels at the algal surface and concluded that our current understanding metal bioavailability is insufficient in terms of describing the internalization of Tm.

The objective of this study was to develop an understanding of the acute toxicity of Tm and the potential for water chemistry to alter responses. H. azteca were used in this study to compare results to those of Borgmann et al. (2005). Additionally, this species was used because they are generally considered to be sensitive to contaminants, are commonly found in fresh waters across North America and there are standardized biological tests method for culturing and testing (Borgmann et al. 1996, Environment Canada 2013), To assess the influence of cationic competition on toxicity responses, tests were done with different concentrations of $\mathrm{Ca}^{2+}, \mathrm{Mg}^{2+}$, and $\mathrm{Na}^{+}$. The potential for DOM to reduce bioavailability via complexation was also tested to determine if the impact of $\mathrm{Tm}$ in aquatic environments is related to its free ion.

\section{Material And Methods}




\section{H. azteca culture}

Culture and test procedures followed the Environment and Climate Change Canada method for $\mathrm{H}$ azteca (Environment Canada 2013). Hyalella were originally collected from the shore of Eabamet Lake at Eabametoong $\mathrm{ON}$ and maintained in the lab for $2 \mathrm{y}$. Collected organisms were identified morphologically as H. azteca (Pennak 1978; Environment Canada 2013). Culture and testing followed the Environment and Climate Change Canada standardized Biological Test Method EPS 1/RM/33 $2^{\text {nd }}$ edition

(Environment Canada, 2013). A reconstituted aquatic medium (RM) was used as described by Vukov et al (2016) and based on a 50\% dilution of the medium described by Borgmann (1996) for Hyalella growth and reproduction. $\mathrm{RM}$ was made with analytical grade $\mathrm{CaCl}_{2}, \mathrm{NaHCO}_{3}, \mathrm{MgSO}_{4}, \mathrm{KCL}$ and $\mathrm{NaBr}$ (SigmaAldrich, Mississauga, $\mathrm{ON}$ ) at 500,500,125, 25 and $5 \mu \mathrm{M}$ respectively to give a hardness of 60 (mg $\mathrm{CaCO}_{3} / \mathrm{L}$ ) and $\mathrm{pH}$ of $7.3 \pm 0.3$. Cultures of $20-30$ adults were kept in $2 \mathrm{~L}$ beakers with $1600 \mathrm{ml}$ of $\mathrm{RM}$ and held at $23^{\circ} \mathrm{C} \pm 2$ in an incubator (LTCB-19 BioChamber, BioChambers Inc., Winnipeg MN) with full spectrum lighting at 500 to 1,000 lux and a 16:8hr light: dark photoperiod. H. azteca were fed on Mon., Wed. and Fri. with $5 \mathrm{mg}$ of finely ground tropical fish food (TetraMin, Tetra, Blacksburg, VA). Neonates between 0 and $7 \mathrm{~d}$ of age were separated from cultures at the weekly media renewal using 650 and 275 $\mu \mathrm{m}$ polyethylene mesh. At RM renewal, a fresh piece of cotton gauze (approx. $5 \times 2.5 \mathrm{~cm}$ ) was added to the beakers (Borgmann 1996).

\section{Acute Tm Toxicity Tests}

Testing procedures followed standard method EPS1/RM/33 for $\mathrm{H}$ azteca (Environment and Climate Change Canada, 2013) with mortality as the endpoint. Acute tests were conducted using 2-9 day old neonates and consisted of 6 exposure concentrations (including unexposed controls). Tm exposure solutions were made using a neutralized ( $\mathrm{pH} 7.3 \pm 0.05)$ stock solution $(30 \mathrm{mg} / \mathrm{L})$ created from an analytical Tm standard (Inorganic Ventures Inc., Christiansburg, VA) in RM. Exposures were done in duplicate in $400 \mathrm{~mL}$ polyethylene beakers (Fischer Scientific, Mississauga ON) with $240 \mathrm{~mL}$ of solution made by appropriate dilution of the stock solution with RM. Test solutions were equilibrated for $24 \mathrm{~h}$ prior to test start $(\mathrm{O} \mathrm{h})$ after which $\mathrm{pH}$ was measured prior to adding Hyalella. A $5 \times 2.5 \mathrm{~cm}$ piece of cotton gauze was separately equilibrated for $24 \mathrm{~h}$ in a $40 \mathrm{~mL}$ plastic cup with $10 \mathrm{~mL}$ of the exposure solution and then added to the exposure beaker along with 10 neonates. Two $15 \mathrm{~mL}$ water samples were taken from each beaker, one was not filtered, and the other was $(45 \mu \mathrm{m}$, HT Tuffryn membrane, Pall, Sigma Aldrich, Mississauga, ON). Test duration was $96 \mathrm{~h}$ at $23^{\circ} \mathrm{C} \pm 2$ with a 16:8 light:dark photoperiod and without feeding. At $96 \mathrm{~h}$ dead and surviving neonates were counted and recorded. As described for test start, two water samples were collected from each exposure solution, the $0.45 \mu \mathrm{m}$ filtered sample was for subsequent measurements of dissolved $\mathrm{Tm}\left(\mathrm{Tm}_{-\mathrm{D}}^{-}\right)$and unfiltered samples for total Tm (Tm- $\left.{ }^{\mathrm{T}}\right)$. All water samples were acidified to $2 \% \mathrm{v} / \mathrm{v}$ with concentrated $\mathrm{HNO}_{3}$ (trace metals grade, Fischer Scientific, Nepean, $\mathrm{ON})$.

To understand the influence of TMFs, acute toxicity tests were done in RM culture medium and then in medium with modifications of either $\mathrm{Ca}, \mathrm{Mg}$, $\mathrm{Na}$ or DOM concentrations. Ca concentrations were adjusted 
by varying the $\mathrm{CaCl}_{2}$ content of RM to achieve either 0.25 or $1.5 \mathrm{mM} \mathrm{Ca}$. Similarly, $\mathrm{MgSO}_{4}$ additions to $\mathrm{RM}$ were varied to achieve $\mathrm{Mg}$ concentrations in test solutions of either 0.07 or $0.38 \mathrm{mM}$. NaCl concentrations of 0.25 or $1.5 \mathrm{mM}$. The effect of DOM on Tm toxicity was tested by addition to achieve nominal concentrations of 3, 7 or $12 \mathrm{mg} \mathrm{DOC/L}$. DOM was collected from Luther Marsh, Grand Valley ON $\left(43^{\circ} 54^{\prime} 17.2^{\prime \prime} \mathrm{N}, 80^{\circ} 24^{\prime} 34.5^{\prime \prime} \mathrm{W}\right)$ by reverse osmosis concentration and the resulting concentrate was kept on ice and returned to Wilfrid Laurier University, treated with an ion exchange resin, acidified to a $\mathrm{pH}<2.5$ and stored in the dark at $4^{\circ} \mathrm{C}$ (Sun et al. 1995; De Schamphelaere et al. 2005). Test solutions with DOM were prepared by diluting appropriate volumes of concentrate in $\mathrm{RM}$ and adjusting $\mathrm{pH}$ to a $\mathrm{pH}$ value of 7.3. Additional $50 \mathrm{ml}$ water samples for $\mathrm{DOC}$ characterization were collected at test end, filtered as previously described $(0.45 \mu \mathrm{m})$ and stored in the dark at $4^{\circ} \mathrm{C}$ until characterization.

\section{Additional Tm Exposure Characterizations}

To assess Tm precipitation in test solutions an independent bench test was conducted with five replicates of five Tm concentrations (nominally $2.2,4.4,8.9,17.8$ and $35.5 \mu \mathrm{M}$ ). Solutions were made with RM into polyethylene beakers and samples (filtered and unfiltered) were collected immediately ( $0 \mathrm{~h}$ ), after $24 \mathrm{~h}$ and $120 \mathrm{~h}$ (the latter two times corresponding to test start and end following equilibration) and acidified as previously described. At $0 \mathrm{~h}$ one of the replicate beakers at each concentration was completely acidified to $2 \%$ ( $\mathrm{vol} / \mathrm{vol}$ ) with trace metals grade $\mathrm{HNO}_{3}$, mixed thoroughly and after approximately an hour a sample was collected in order to assess recovery of $\operatorname{Tm}_{-T}\left(\mathrm{Tm}_{-\mathrm{Rec}}\right)$ relative to nominal concentrations. At 120 hours, after sampling, the remaining four beakers were similarly acidified and samples collected for $\mathrm{Tm}_{\text {-Rec }}$. Care was taken not to disturb solutions before sample collection except in the case of the complete acidification of beaker contents where a thorough mixing was done after addition of acid.

\section{Sample Measurements and Calculation and Statistics}

Measured concentrations were determined for both $\mathrm{Tm}_{-\top}$ and $\mathrm{Tm}_{-\mathrm{D}}$ using the inductively coupled plasma optical emission spectroscopy (ICP-OES, Optima 8000, Perkin-Elmer Inc. Woodbridge, ON) as well as all solution cations $(\mathrm{Ca}, \mathrm{Na}, \mathrm{Mg})$. Analysis parameters and wavelengths were selected using manufacturer guidelines and recommendations. Samples, particularly RM without addition of Tm were sent for Tm characterization by ICP-MS at the GRIL (Groupe de Recherche Interuniversitaire en Limnologie) Labs at the Université de Montréal. Measured background for Tm in the RM medium was $0.005 \mu \mathrm{g} / \mathrm{L}$ for $\mathrm{Tm}_{-\mathrm{T}}$ and $0.001 \mu \mathrm{g} / \mathrm{L}_{\text {for }} \mathrm{Tm}_{-\mathrm{D}}$. DOC concentrations were measured by combustion catalytic oxidation using a total organic carbon analyzer (TOC-LCPH, Shimadzu Corporation, Mandel Scientific, Guelph, ON).

Concentrations associated with $50 \%$ lethality after $96 \mathrm{~h}$ of exposure $\left(\mathrm{LC}_{50}\right)$ were calculated for measured concentrations of both $\mathrm{Tm}_{-}{ }_{\top}$ and $\mathrm{Tm}_{-\mathrm{D}}$ measured concentrations at $96 \mathrm{~h}$ using probit analysis in SPSS (IBM SPSS Statistics for Windows). Significant differences between LC $_{50}$ values were established based on overlap of confidence intervals as described by Litchfield and Wilcoxon (1949, cited in Environment Canada, 2005). 


\section{Results And Discussion}

\section{Tm Water Chemistry and Characterization}

In the trial to characterize Tm concentrations in RM only (H. azteca not exposed), the $\mathrm{Tm}_{\text {-Rec }}$ concentrations were generally less than the planned nominal concentrations (Table 1). As nominal concentrations increase the proportion of recovered Tm was reduced (except at the highest concentration, Table 1). Measured $\mathrm{Tm}_{-}{ }_{\top}$ and $\mathrm{Tm}_{-\mathrm{D}}$ concentrations generally showed increasing amounts of precipitation as the nominal and $\mathrm{Tm}^{-}{ }_{\text {Rec }}$ concentrations increased. Immediately after solutions were created ( $0 \mathrm{~h}$ time) there were differences between $\mathrm{Tm}_{-}^{\top}$ and $\mathrm{Tm}_{-\mathrm{D}}$ concentrations but by $24 \mathrm{~h}$ the solution $\mathrm{Tm}$ concentrations appeared to stabilize and there were no differences between $\mathrm{Tm}_{-}^{-}$and $\mathrm{Tm}_{-\mathrm{D}}$ concentrations over the next $96 \mathrm{~h}$ (Table 1). Following equilibration there was a clear pattern of increased precipitation of Tm at higher concentrations with an apparent solubility threshold of approximate 3-4 $\mu \mathrm{M} \mathrm{Tm}^{-}{ }_{\text {Rec }}$. At the highest of the prepared concentrations $84 \%(24 \mathrm{~h})$ and $87 \%(120 \mathrm{~h})$ of the Tm that had been added to the beaker (as measured by $\mathrm{Tm}^{-}{ }_{\mathrm{Rec}}$ ) was in an insoluble form.

Overall, the bench test results illustrated that there was likely precipitation occurring in the stock solution used to prepare exposure solutions (nominal vs $\mathrm{Tm}_{\text {-Rec }}$ concentration differences in Table 1). This was anticipated because the stock solution was adjusted to $\mathrm{pH}$ 7.3. From experience, the use of an acidified stock solution results in recovered concentrations being much closer to nominal however it also produces significant differences in solution $\mathrm{pH}$ across the concentration range and the process of solution-bysolution $\mathrm{pH}$ adjustment can be exceptionally time-consuming. By using a stock solution with a pH that matched that of the RM we reduced the need to adjust the $\mathrm{pH}$ of each test solution but the trade-off was variation in $\mathrm{Tm}$ concentrations. Of key importance is measurement of $\mathrm{Tm}_{-T}$ and $T \mathrm{~m}_{-\mathrm{D}}$ at the beginning and the end of the test. Data from the bench test indicated that $24 \mathrm{~h}$ was sufficient for test solution equilibration as there were few differences between $120 \mathrm{~h}$ and $24 \mathrm{~h}$ concentrations (Table 1). There were indications of significant precipitation and at the highest concentrations with only $13-17 \%$ of the Tm was in the dissolved form (Table 1).

Precipitation is recognized as a complicating factor in REE toxicity tests (Gonzalez et al. 2014). Borgmann et al. (2005) reported a nominal LC50 of $721 \mathrm{ug} \mathrm{Tm/L}$ with a measured LC50 of $0.01 \mathrm{ug}$ $\mathrm{Tm} / \mathrm{L}$. In aquatic toxicity tests La readily precipitated out of solution and measured values were always less than $30 \%$ of the nominal concentrations (Barry and Meehan 2000). Ce, Gd and Nd precipitated from solution as concentration increased and also over time (up to $72 \mathrm{~h}$, Blinova et al. 2019). Vukov et al. (2016) found that precipitation of Dy correlated with increased exposure concentration. It was reported that at high exposure concentrations of Dy, dissolved concentrations were less than $34 \%$ of total concentrations (Vukov et al. 2016). Precipitation can likely be accounted for by the $\mathrm{pH}$ and the carbonate content of RM and the formation of insoluble salts (Jiang and Ji 2012; Janssen and Verweij 2003). The study of Gonzalez et al. (2015) also reported the formation of "insoluble species" in REE test 
solutions and used geochemical modelling to show that hydroxide and carbonate precipitation was expected.

\section{Tm acute toxicity in RM}

H. azteca mortality increased with increasing concentrations of Tm (Table 2). Based on the results from the bench test, we expected measured Tm concentrations at test beginning and at test end to be relatively similar however, this was not always the case (Table 2). An equilibration time of $24 \mathrm{~h}$ may not have been sufficient and it is unknown if the addition of organisms influenced the geochemistry of test solutions. Calculations of the standard acute toxicity endpoint ( 96 h LC50) were done with measured concentrations and this was possible for both $\mathrm{Tm}_{-T}$ or $\mathrm{Tm}_{-D}$ and either at the beginning of the test or at the end (Table 2). In general, the measured concentrations were lowest at the end of the tests and therefore, as a conservative approach, calculations were based on samples collected at $96 \mathrm{~h}$.

In unaltered RM the $96 \mathrm{~h} \mathrm{LC50}$ value for measured dissolved was $573 \mu \mathrm{g} / \mathrm{L}(3.4 \mu \mathrm{M})$ with $95 \%$ confidence interval from 482 to $663 \mu \mathrm{g} / \mathrm{L}(2.9-3.9 \mu \mathrm{M}$; Fig 1, light gray bar at $0.5 \mathrm{mM} \mathrm{Ca})$. This concentration is much higher than the $7 \mathrm{~d}$ LC50 value of $0.01 \mu \mathrm{g} / \mathrm{L}$ previously reported (Borgmann et al. 2005) for measured $\mathrm{Tm}_{-\mathrm{D}}$ in soft water. Compared to our study, Borgmann et al. (2005) conducted static tests for a longer duration ( 4 vs $7 \mathrm{~d}$ ) in softer water (hardness value 60 vs $12 \mathrm{mg} \mathrm{CaCO} / \mathrm{L}$ ) and with feeding part way through (our tests were without food). While exposure duration, geochemistry and the provision of food are recognized as potential influences on the bioavailability and toxicity of metals, it is unknown if these can explain the dramatically different results (57,000 fold difference in LC50 values). Interestingly, the nominal $7 \mathrm{~d}$ LC50 values reported by Borgmann et al. (2005) were $721 \mu \mathrm{g} / \mathrm{L}$ in soft water and 739 $\mu \mathrm{g} / \mathrm{L}$ in hard water and this compares well to our estimate of $1062 \mu \mathrm{g} / \mathrm{L}$ for the $96 \mathrm{~h} \mathrm{LC50}$ on a nominal basis (using the $\mathrm{Tm}_{-D}$ to nominal $\mathrm{Tm}$ relationship in the test to estimate). The very low $\mathrm{Tm}_{-\mathrm{D}}$ value previously reported by Borgmann et al. (2005) remains unexplained and it is worth noting that the authors of the work do not offer any discussion of it what-so-ever. Their analysis and discussion of Tm toxicity used the nominal based toxicity endpoints exclusively.

\section{Influence of Cations on Tm toxicity}

The results for effects of $\mathrm{Ca}$ on Tm toxicity (Fig. 1) were somewhat difficult to interpret. On the basis of $\mathrm{Tm}_{-\mathrm{T}}$ concentrations the lowest LC50 was at the $0.5 \mathrm{mM}$ Ca treatment and toxicity was significantly reduced at both lower and higher concentrations ( 0.25 and 1.5 respectively). However, for $\mathrm{Tm}_{-\mathrm{D}}$ there was no trend evident for the low Ca exposure because the LC50 values at 0.25 and $0.5 \mathrm{Ca}$ were not significantly different. At the higher Ca treatment $\mathrm{Tm}_{-D}$ showed higher toxicity (Fig 1 ). There was no protective effect with increasing Na concentrations (Fig. 2). Similarly, we did not see a protective effect with $\mathrm{Mg}$ as there were no significant differences in LC50 values across the range of $\mathrm{Mg}$ tested (Fig. 3). 
We hypothesized that increases in Ca would have a protective effect to Tm toxicity but there was no consistent trend across the range of Ca tested (Fig 1). Other studies have shown that Ca provides significant protection against the toxicity of REEs. For example, Vukov et al. (2016) showed a 1.8-fold decrease in Dy toxicity to H. azteca over a 3-fold increase in Ca concentration. Barry and Meehan (2000) showed that La toxicity to Daphnia carinata was reduced as hardness increased. Cardon et al. 2019 and Ma et al. 2016, with $Y$ and $\mathrm{Ce}$ (respectively) similarly demonstrated reduced toxicity to $D$. magna with increased hardness. In these studies the changes in toxicity are linked to hardness and so cannot be exclusively attributed to $\mathrm{Ca}$. As discussed above, changes in exposure hardness did not result in changes of Tm toxicity (Borgmann et al 2005) and this is consistent with our results but only nominal LC50 values are available. It may be that $\mathrm{Tm}$ uptake and toxicity is not influenced by competitive interaction with $\mathrm{Ca}$ and therefore it is unlike other REEs (e.g. Dy, La, Ce and Y) that are. There was no protective effect with increasing Na concentrations (Fig. 2) and this result is different to the Vukov et al., (2016) study where a 3 fold increase of Na significantly decreased Dy toxicity by a factor of 1.4 times. However, these results were based on total Dy concentrations and the study states that LC50s for dissolved Dy concentrations were much less clear (Vukov et al. 2016). Out results with Mg align with those of Vukov et al. (2016) where $\mathrm{Mg}$ additions did not show a protective effect on Dy toxicity.

We had hypothesized that $\mathrm{Tm}$ toxicity would be influenced by cationic competition, particularly $\mathrm{Ca}^{2+}$. Previous studies on the toxicity of inorganic forms of metals attribute the toxicity reduction achieved by cations to direct competition at the site of uptake of essential ions such as $\mathrm{Ca}^{2+}$ and $\mathrm{Na}^{+}$(Niyogi and Wood 2004). Toxic metals have similar characteristics (e.g. ionic radius and charge) compared to essential ions and via ionic mimicry (Bridges and Zalups 2005) divalent metal cations such as $\mathrm{Cd}^{2+}, \mathrm{Zn}^{2+}$ and $\mathrm{Pb}^{2+}$ inhibit $\mathrm{Ca}^{2+}$ uptake while monovalent metals such as $\mathrm{Ag}^{+}$disrupting $\mathrm{Na}^{+}$uptake (Niyogi and Wood 2004). From this perspective the mechanism by which a trivalent REE free ion would interact (compete) with an essential divalent ( $\mathrm{Ca}$ or $\mathrm{Mg}$ ) or monovalent $\mathrm{(Na}$ ) cation is not clear. However, studies have highlighted the similar properties of trivalent REEs, particularly in relation to $\mathrm{Ca}^{2+}$ (Evans 1983) and it is well known that $\mathrm{La}^{3+}$ is an effective analogue. There is some evidence of direct competition between $\mathrm{Ca}^{2+}$ and trivalent REEs in algae. $\mathrm{Ca}^{2+}$ competitively inhibit $\mathrm{La}^{3+}$ and $\mathrm{Ce}^{3+}$ uptake and protect against toxicity in Chlorella fusca (Aharchaou et al. 2020). A 1000 fold increase in Ca concentration ( $1 \mu \mathrm{M}-1$ $\mathrm{mM}$ ) resulted in a 2 fold (La exposure) and 3 fold (Ce exposure) increase in cell density over $120 \mathrm{~h}$ of exposure (Aharchaou et al. 2020). Tests with $C$ reinhardtii demonstrated competition with reduced $\mathrm{Nd}^{3+}$ (Yang and Wilkinson 2018) and $\mathrm{Sm}^{3+}$ (Tan et al. 2017) uptake as either $\mathrm{Ca}^{2+}$ or $\mathrm{Mg}^{2+}$ increased. In our experiments neither $\mathrm{Ca}, \mathrm{Mg}$ nor $\mathrm{Na}$ influenced $\mathrm{Tm}$ toxicity to Hyalella. Understanding the mechanisms of uptake of Tm in aquatic invertebrates would also be valuable in understanding the potential for toxicity mitigation in natural waters.

\section{Influence of DOM on Tm toxicity}


In solutions with added Luther Marsh DOM toxicity was significantly reduced above concentrations of $3 \mathrm{mg} \mathrm{DOC/L}$ (Fig 4). The addition of DOM also altered the relative concentrations of $\mathrm{Tm}_{-\mathrm{T}}$ and $\mathrm{Tm}_{-\mathrm{D}}$ and it appeared that the precipitation threshold may have been increased with elevated DOC content (Table 2). DOM has been shown to reduce the toxicity of numerous metals in a concentration dependent manner (Wood et al. 2011). It is a complex heterogeneous molecule with a variety of negatively charged moieties that are capable of interacting with cationic metals. Complexation of the free ion form of the metal reduces the availability for uptake thereby reducing toxicity. This was evident in our study for Tm (Fig 4) and we assumed that mitigation of toxicity was due to reduced $\mathrm{Tm}^{3+}$ concentrations. However, this is only an assumption as the bioavailable forms of Tm associated with toxicity and the mechanism of uptake at the biotic surface are unknown.

While we did not measure free ion concentrations of $\mathrm{Tm}^{3+}$ in solution, we did use the geochemical equilibrium modeling software WHAM (Windermere Humic Aqueous Model, Ver 7.02; Tipping et al. 2011) to estimate $\mathrm{Tm}^{3+}$. Using the $\mathrm{Tm}_{-\mathrm{D}}$ and measured DOC concentrations at the end of the test as model inputs as described by Stockdale et al (2015), WHAM predicted virtually complete complexation of Tm. The predicted $\mathrm{Tm}^{3+}$ concentrations in test solutions with added DOM were at least 140 fold lower (highest $\mathrm{Tm}_{-D}$ with lowest DOC) and ranged up to $2.5 \times 10^{6}$ fold lower (lowest $\mathrm{Tm}_{-\mathrm{D}}$ with highest DOC) than the corresponding $\mathrm{Tm}^{3+}$ concentrations in solutions with no added DOM. Clearly the predicted $\mathrm{Tm}^{3+}$ estimates were not linked to the acute toxicity of $\mathrm{Tm}$. One possible conclusion is that $\mathrm{Tm}^{3+}$ is not associated with toxicity in Hyalella and that other (or additional) geochemical forms are. It is also possible that WHAM is predicting a much higher level of complexation of $\mathrm{Tm}^{3+}$ than is actually occurring in our test solutions. Either way, DOM significantly reduces Tm toxicity and an improved understanding of the geochemical speciation of $\mathrm{Tm}$ in relation to acute toxicity is required.

There are relatively few studies on the effects of REEs on aquatic biota and even fewer investigating the potential influence of DOM on toxicity. DOM has been highlighted as an important factor to include in water quality derivations for La (Hermann et al 2016). Vukov et al (2016) used Suwannee River DOM to show 3-4 fold reductions of Dy toxicity to Hyalella at a DOC concentration of $13 \mathrm{mg} / \mathrm{L}$. The biouptake of $\mathrm{Sm}^{3+}$ (as measured directly by ion exchange technique) into the unicellular green algae Chlamydomonas reinhardtii was significantly reduced by DOM in a DOC concentration dependent manner (Rowell et al 2018). In that study four different sources of DOM were tested, including Luther Marsh DOM, and even very small additions of $0.5 \mathrm{mg} \mathrm{DOC/L}$ dramatically reduced uptake by 10 fold (Rowell et al 2018). In tests with the synthetic organic ligands malic acid, diglycolic acid and citric acid, Sm uptake to $C$. reinhardtii was reduced but the possibility of complexed $\mathrm{Sm}$ also being taken up could not be ruled out (Tan et al 2016). Similar reduced uptake results into Chlorella vulgarize were shown for La, Gd and Y using the organic ligands citrate, nitriloacetic acid and ethylenediamine tetraacetic acid (Sun et al 1997). In natural waters the important role that DOM has in complexing REEs is well recognized (Moermond et al 2001; Tang and Johannesson 2003, Tipping and Filella 2020) and it is generally assumed that complexation will reduce toxicity (Herrmann et al 2016). Given the ubiquitous nature of DOM in natural waters and the significant reduction in toxicity we observed, further study on DOM-Tm interactions would 
contribute to the development of water quality thresholds for assessing the environmental risk of this REE.

\section{Conclusions}

This study provided data on the role of water chemistry in the toxicity of Tm to aquatic invertebrates. As observed in other studies, the formation of insoluble species can predominate at elevated concentrations. While we equilibrated our test solutions for $24 \mathrm{~h}$ before beginning tests, this may not have been sufficient, and we observed $\mathrm{Tm}_{-T}$ and $\mathrm{Tm}_{-D}$ changes between the beginning and end of tests. LC50 determinations based on measured concentrations at the end of the test provided a conservative approach to characterizing effects. In tests with different concentrations of $\mathrm{Ca}$ or $\mathrm{Na}$ or $\mathrm{Mg}$ we found no consistent toxicity modification and conclude that cationic competition does not influence $\mathrm{Tm}$ toxicity. This would appear to be unlike some of the other REEs where cations, or more commonly, water hardness has been shown to reduce toxicity. Acute toxicity was influenced by DOM and concentrations above $3 \mathrm{mg} \mathrm{DOC/L}$ resulted in significantly increased $96 \mathrm{~h}$ LC50 values. In estimating the potential of Tm effects in natural water it appears that complexation is an important consideration.

\section{Declarations}

Funding - see Acknowledgements

Conflicts of interest/Competing interests - The authors have no conflicting/competing financial interests nor personal relationships that influence the work reported in this paper.

\section{Availability of data and material - Data is available from the corresponding author \\ Code availability - Not applicable}

Ethics approval - Not applicable

Consent to participate - Not applicable

Consent for publication - Not applicable

Acknowledgements The authors are grateful for the technical expertise and assistance of Gena Braun of the Centre for Cold Regions and Water Science as well as Jonathan Ford from the Biology Department at Laurier. This research was funded via a contribution agreement with Environment and Climate Change Canada and Strategic Grants from the Natural Sciences and Engineering Research Council of Canada with additional contributions/participation from Avalon Advanced Materials Inc., Ontario Ministry of Environment, Conservation and Parks, International Zinc Association and Natural Resources Canada.

\section{References}


1. Aharchaou I, Beaubien C, Campbell PGC, Fortin C (2020) Lanthanum and cerium toxicity to the freshwater green alga Chlorella fusca: Applicability of the biotic ligand model. Environ Toxicol Chem 39: 996-1005. https://doi.org/10.1002/etc.4707

2. Al-Reasi HA, Wood CM, Smith DS (2013) Characterization of freshwater natural dissolved organic matter (DOM): mechanistic explanations for protective effects against metal toxicity and direct effects on organisms. Environ Internat 59: 201-207. https://doi.org/10.1016/j.envint.2013.06.005

3. Barry MJ, Meehan BJ (2000) The acute and chronic toxicity of lanthanum to Daphnia carinata. Chemoshpere 41: 1669-1674. https://doi.org/10.1016/S0045-6535(00)00091-6

4. Blinova I, Lukjanova A, Muna M, Vija H, Kahru A (2018) Evaluation of the potential hazard of lanthanides to freshwater microcrustaceans. Sci Tot Environ 642: 1100-1107. https://doi.org/10.1016/j.scitotenv.2018.06.155

5. Borgmann U (1996) Systematic analysis of aqueous ion requirements of Hyalella azteca: a standard artificial medium including the essential bromide ion. Arch Environ Contam Toxicol 30: 356363. https://doi.org/10.1007/BF00212294

6. Borgmann U, Couillard Y, Doyle P, Dixon GD (2005) Toxicity of sixty-three metals and metalloids to Hyalella azteca at two levels of water hardness. Environ Toxicol Chem 24: 641-652. https://doi.org/10.1897/04-177R.1

7. Bridges CC, Zalups RK (2005) Molecular and ionic mimicry and the transport of toxic metals. Toxicol App Pharmacol 204: 274-308. https://doi.org/10.1016/j.taap.2004.09.007

8. Cardon P-Y, Triffault-Bouchet G, Caron A, Rosabal M, Fortin C, Amyot M (2019) Toxicity and subcellular fractionation of yttrium in three freshwater organisms: Daphnia magna, Chironomus riparius, and Oncorhynchus mykiss. ACS Omega 4: 13747-13755. https://doi.org/10.1021/acsomega.9b01238

9. De Schamphelaere KAC, Unamuno VIR, Tack FMG, Vanderdeelen J, Janssen CR (2005) Reverse osmosis sampling does not affect the protective effect of dissolved organic matter on copper and zinc toxicity to freshwater organisms. Chemosphere 58: 653-658. https://doi.org/10.1016/j.chemosphere.2004.06.039

10. Di Toro DM, Allen HE, Bergman HL, Meyer JS, Paquin PR, Santore RC (2001) Biotic ligand model of the acute toxicity of metals. 1. Technical basis. Environ Toxicol Chem 20: 2383-2396. https://doi.org/10.1002/etc.5620201034

11. El-Akl P, Smith S, Wilkinson KJ (2015) Linking the chemical speciation of cerium to its bioavailability in water for a freshwater alga. Environ Toxicol Chem 34: 17111719. https://doi.org/10.1002/etc.2991

12. Environment Canada (2005) Guidance document on statistical methods for environmental toxicity tests. Environment Canada, Method Development and Applications Section. Ottawa. ON. Report EPS 1/RM/46. June 2007 amendments. 241 pp.

13. Environment Canada (2013) Biological test method: test for survival and growth in sediment and water using the freshwater amphipod Hyalella azteca. Environmental Protection Service. Ottawa ON. 
Report EPS 1/RM/33 $2^{\text {nd }}$ edition $151 \mathrm{pp}$.

14. Evans $\mathrm{CH}$ (1983) Interesting and useful biochemical properties of lanthanides. Trends Biochem Sci 8:445-449. https://doi.org/10.1016/0968-0004(83)90032-4

15. Gonzalez V, Vignati DAL, Leyval C, Giamberini L (2014) Environmental fate and ecotoxicity of lanthanides: Are they a uniform group beyond chemistry? 71: 148-

157. https://doi.org/10.1016/j.envint.2014.06.019

16. Gonzalez V, Vignati DAL, Pons MN, Montarges-Pelletier E, Bojic C, Giamberini L (2015) Lanthanide ecotoxicity: first attempt to measure environmental risk for aqautic organisms. Environ Pollut 199: 139-147. https://doi.org/10.1016/j.envpol.2015.01.020

17. Gwenzi W, Mangori L, Danha C, Chaukura N, Dunjana N, Sanganyado E (2018) Sources, behaviour, and environmental and human health risks of high-technology rare earth elements as emerging contaminants. Sci Tot Environ 636: 299-313. https://doi.org/10.1016/j.scitotenv.2018.04.235

18. Humphries M (2013) Rare earth element: the global supply chain. Congressional Research Service, Washington, DC. Report R41347. 31 pp.

19. Herrmann H, Nolde J, Berger S, Heise S (2016) Aquatic ecotoxicity of lanthanum - A review and an attempt to derive water and sediment quality criteria. Ecotoxicol Environ Saf 124: 213-238. https://dx.doi.org/10.1016/j.ecoenv.2015.09.033

20. Janssen RPT, Verweij W (2003) Geochemistry of some rare earth elements in groundwater, Vierlingsbeek, the Netherlands. Water Res 37: 1320-1350. https://doi.org/10.1016/S00431354(02)00492-X

21. Jiang Y, Ji H (2012). Rare earth geochemistry in the dissolved suspended and sedimentary loads in karstic rivers, Southwest China. Environ Earth Sci 66: 2217-2234. https://doi.org/10.1007/s12665011-1443-8

22. Litchfield JT, Wilcoxon F (1949) A simplified method of evaluating dose-effect experiments. J Pharmacol Exp Ther 96: 99-113.

23. Ma Y, Wang J, Peng C, Ding Y, He X, Zhang P, Li N, Lan T, Wang D, Zhang Z, Sun F, Liao H, Zhang Z (2016) Toxicity of cerium and thorium on Daphnia magna. Ecotoxicol Environ Saf 134: 226232. https://dx.doi.org/10.1016/j.ecoenv.2016.09.006

24. Mebane CA, Chowdhury J, De Schamphelaere KAC, Lofts S, Paquin PR, Santore RC, Wood CM (2020) Metal Bioavailability Models: Current Status, Lessons Learned, Considerations for Regulatory Use, and the Path Forward. Environ Toxicol Chem 39: 60-84. https://doi.org/10.1002/etc.4560

25. Moermond CTA, Tijink J, Van Wezel AP, Koelmans AA (2001) Distribution, speciation, and bioavailability of lanthanides in the Rhine-Meuse estuary, the Netherlands. Environ Toxicol Chem 20: 1916-1926. https://doi.org/10.1002/etc.5620200909

26. Niyogi S, Wood CM (2004) Biotic ligand model: a flexible tool for developing site-specific water quality guidelines for metals. Environ Sci Technol 38: 6177 - 6192.

https://doi.org/10.1021/es0496524 
27. Rowell J-A, Fillion M-A, Smith S, Wilkinson KJ (2018) Determination of the speciation and bioavailability of samarium to Chlamydomonas reinhardtii in the presence of natural organic matter. Environ Toxicol Chem 37: 1623-1631. https://doi.org/10.1002/etc.4106

28. Santore RC, Di Toro DM, Paquin PR, Allen HE, Meyer JS (2001) Biotic ligand model of the acute toxicity of metals 2. Application to copper toxicity in freshwater fish and daphnia. Environ Toxicol Chem 20: 2397-2402. https://doi.org/10.1002/etc.5620201035

29. Stockdate A, Tipping E, Lofts S (2015) Dissolved trace metal speciation in estuarine and coastal waters: comparison of WHAM/Model VII predictions with analytical results. Environ Toxicol Chem 34: 53-63. https://doi.org/10.1002/etc.2789

30. Sun H, Wang X, Wang L, Dai L, Li Z, Cheng Y (1997) Bioconcentration of rare earth elements lanthanum, gadolinium and yttrium in algae (Chlorella Vulgarize Beijerinck): Influence of chemical species. Chemosphere 34: 1753-1760. https://doi.org/10.1016/S0045-6535(97)00031-3

31. Sun L, Perdue EM, McCarthy JF (1995) Using reverse osmosis to obtain organic matter from surface and ground waters. Wat Res 29: 1471-1477. https://doi.org/10.1016/0043-1354(94)00295-I

32. Tan Q-G, Yang G, Wilkinson KJ (2016) Biotic ligand model explains the effects of competition but not complexation for Sm biouptake by Chlamydomonas reinhardtii. Chemosphere 168: 426-434. https://dx.doi.org/10.1016/j.chemosphere.2016.10.051

33. Tanentzap AJ, Szkokan-Emilson ES, Kielstra B, Arts MT, Yan ND, Gunn JM (2014) Forests fuel fish growth in freshwater deltas. Nat Commun 5: 4077. https://doi.org/10.1038/ncomms5077

34. Tang J, Johannesson KH (2003) Speciation of rare earth elements in natural terrestrial waters: assessing the role of dissolved organic matter from the modeling approach. Geochim Cosmochim Acta 67: 2321-2339. https://doi.org/10.1016/S0016-7037(02)01413-8

35. Tipping E, Filella M (2020) Estimation of WHAM7 constants for Gall', In ${ }^{I I I}, \mathrm{Sb}^{\mathrm{III}}$ and $\mathrm{Bi}^{\mathrm{III}}$ from linear free energy relationships, and speciation calculations for natural waters. Environ Chem 17: 140-147. https://doi.org/10.1071/EN19194

36. Tipping E, Lofts S, Sonke JE (2011) Humic lon-Binding Model VII: a revised parameterisation of cation-binding by humic substances. Environ Chem 8: 225-235 https://doi.org/10.1071/EN11016

37. Vukov O, Smith DS, McGeer JC (2016) Acute dysprosium toxicity to Daphnia pulex and Hyalella azteca and development of the biotic ligand approach. Aquat Toxicol 170: 142 - 151. https://doi.org/10.1016/j.aquatox.2015.10.016

38. Wood CM, Al-Reasi HA, Smith DS (2011) The two faces of DOC. Aquat Toxicol 105S: 38. https://doi.org/10.1016/j.aquatox.2011.03.007

39. Yang G, Wilkinson KJ (2018) Biouptake of a rare earth metal (Nd) by Chlamydomonas reinhardtii Bioavailability of small organic complexes and role of hardness ions. Environ Pollut 243A: 263269. https://doi.org/10.1016/j.envpol.2018.08.066

40. Yin X, Martineua C, Demers I, Basiliko N, Fenton NJ (2021) The potential environmental risks associated with the development of rare earth element production in Canada. Environ Rev 12 March 2021 Canadian Science Publishing. https://doi.org/10.1139/er-2020-0115 
41. Zhao CM, Wilkinson KJ (2015) Biotic ligand model does not predict the bioavailability of rare earth elements in the presence of organic ligands. Environ Sci Technol 49: 2207-2214 https://doi.org/10.1021/es505443s

\section{Tables}

Due to technical limitations, table 1-2 is only available as a download in the Supplemental Files section.

\section{Figures}

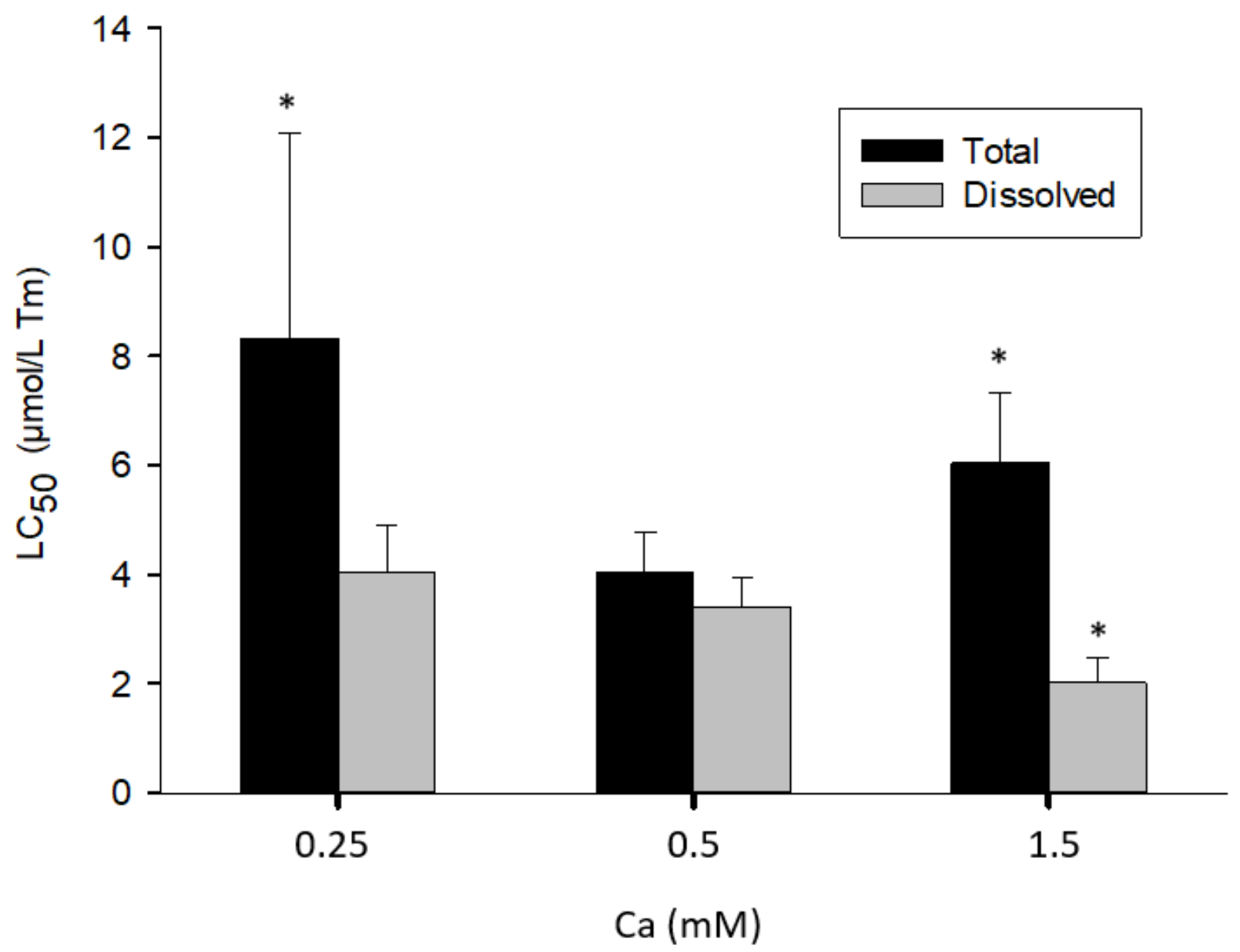

\section{Figure 1}

The $96 \mathrm{~h}$ LC50 values (with upper 95\% confidence intervals) for Hyalella azteca exposure to Tm at different $\mathrm{Ca}$ concentrations. The LC50 values are based on measured total (Tm-T black bars) and measured dissolved (Tm-D grey bars) concentrations at the end of the test. The asterisks indicate LC50 values significantly different for either Tm-T or Tm-D from the corresponding acute test in RM at $0.5 \mathrm{mM}$ Ca. 


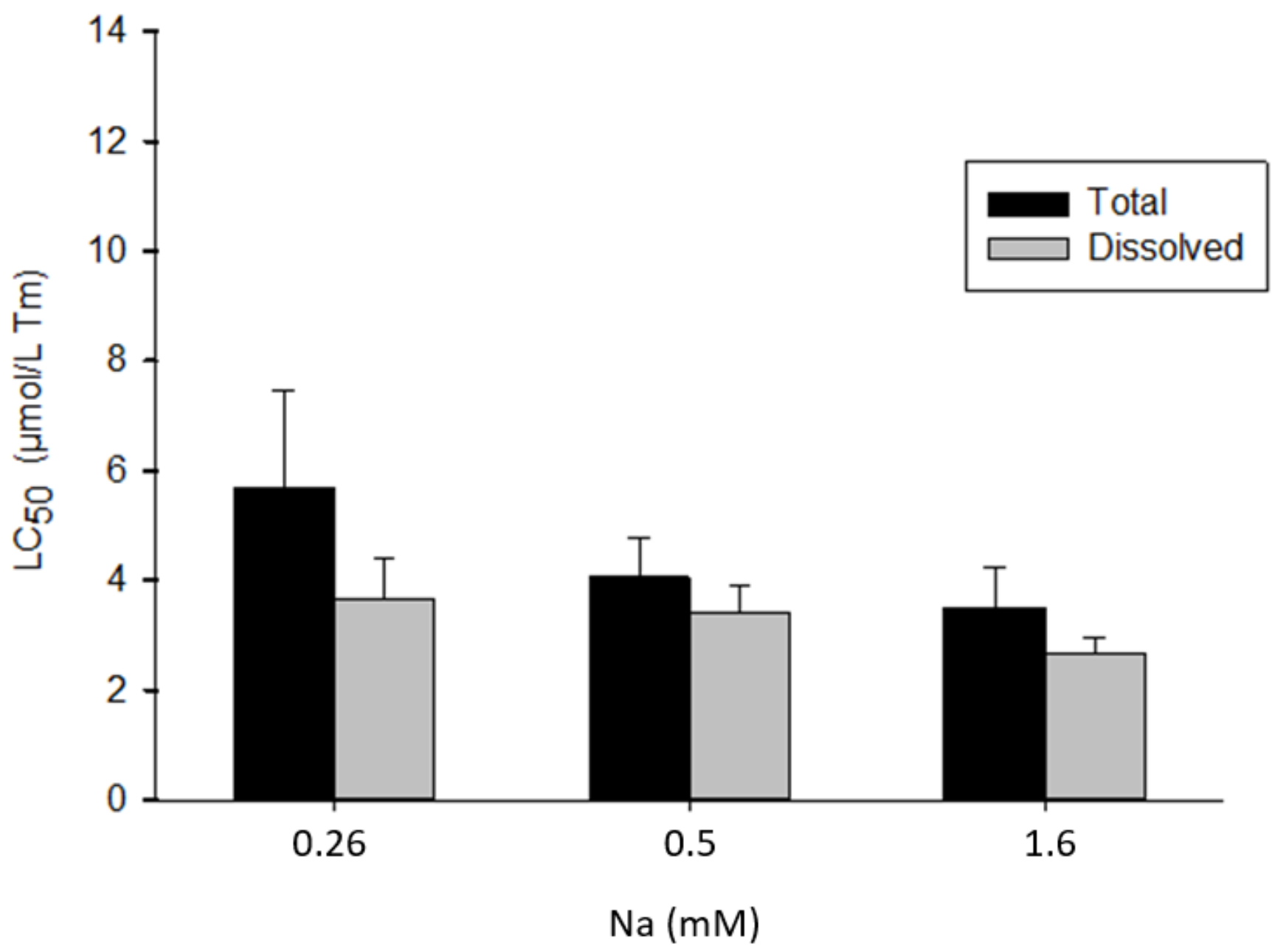

Figure 2

The $96 \mathrm{~h}$ LC50 values (with upper 95\% confidence intervals) for Hyalella azteca exposure to Tm at different Na concentrations. The LC50 values are based on measured total (Tm-T black bars) and measured dissolved (Tm-D grey bars) concentrations at the end of the test. There were no significant differences for either Tm-T or Tm-D compared to the corresponding acute test in RM at $0.5 \mathrm{mM} \mathrm{Na}$. 


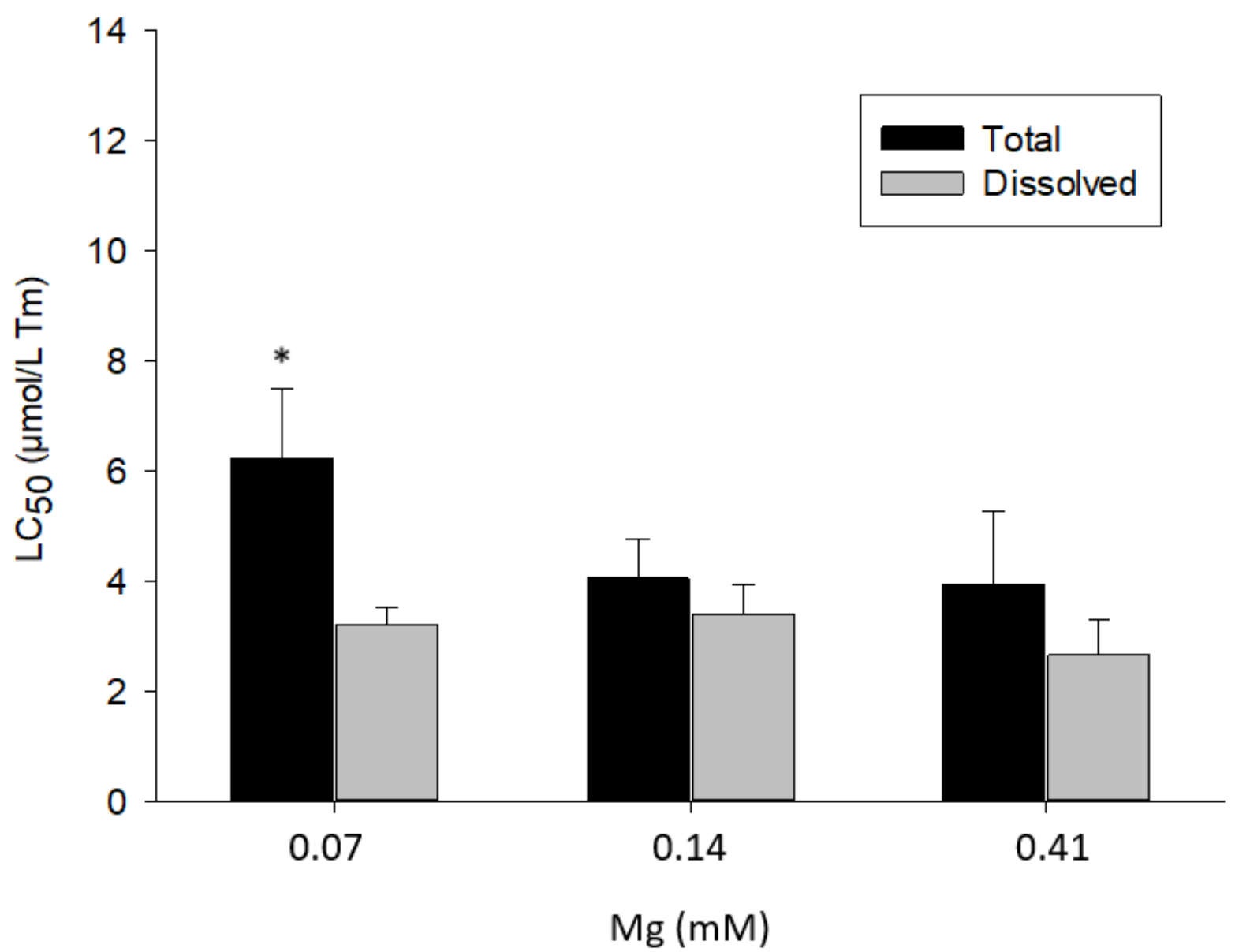

Figure 3

The $96 \mathrm{~h}$ LC50 values (with upper 95\% confidence intervals) for Hyalella azteca exposure to Tm at different Mg concentrations. The LC50 values are based on measured total (Tm-T black bars) and measured dissolved (Tm-D grey bars) concentrations at the end of the test. The asterisks indicate LC50 values significantly different for either Tm-T or Tm-D from the corresponding acute test in RM at $0.5 \mathrm{mM}$ $\mathrm{Mg}$. 


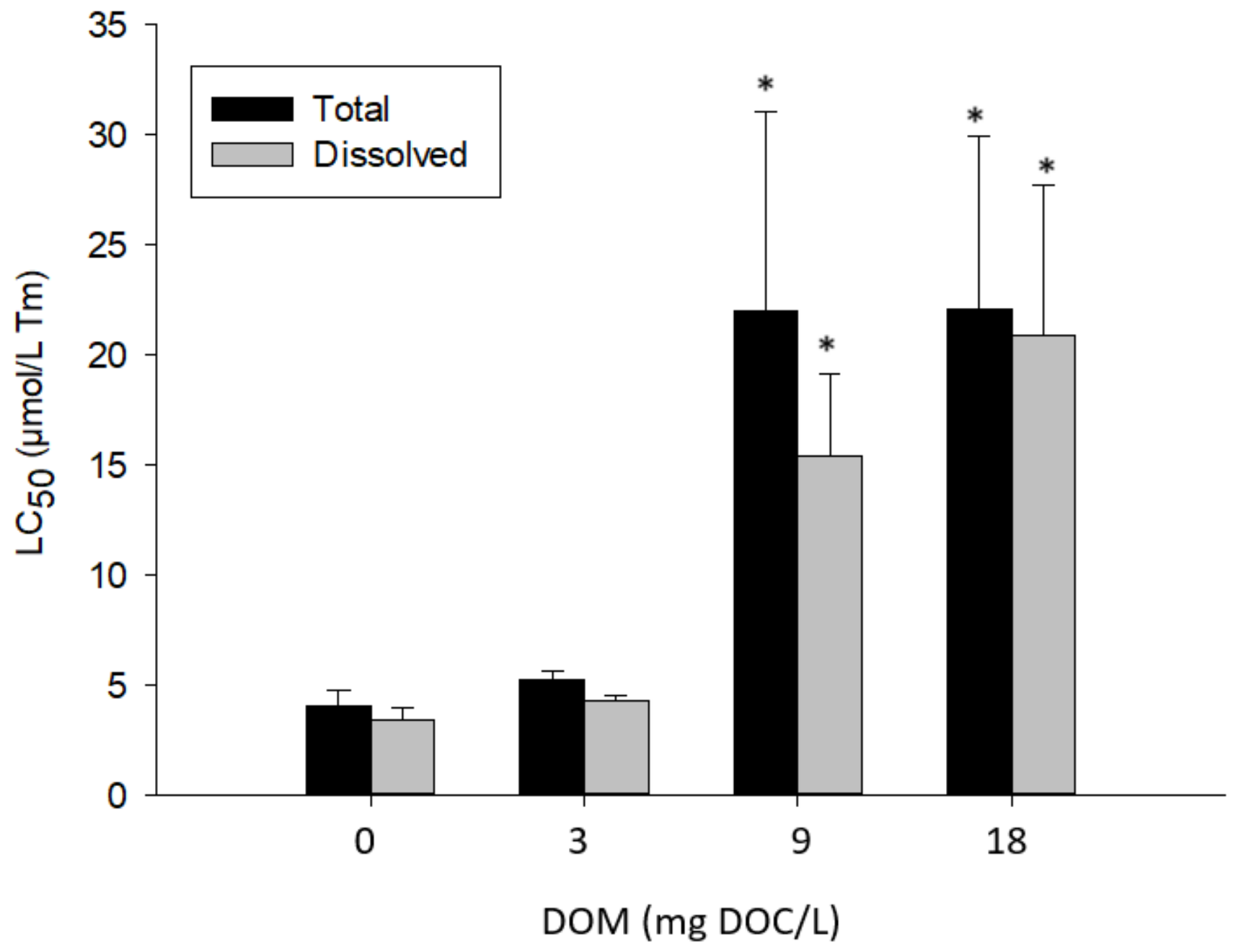

Figure 4

The $96 \mathrm{~h}$ LC50 values (with upper 95\% confidence intervals) for Hyalella azteca exposed to Tm with added Luther Marsh DOM (measured as mg DOC/L). LC50 values are based concentrations measured at the end of the tests for Tm-T (black bars) and Tm-D (grey bars). An * indicates a LC50 value significantly different for either Tm-T or Tm-D compared to the corresponding test in RM with no added DOM ( $0 \mathrm{mg}$ $\mathrm{DOC} / \mathrm{L})$.

\section{Supplementary Files}

This is a list of supplementary files associated with this preprint. Click to download.

- Tables.pdf 